\title{
Strut-and-tie models for linear and nonlinear behavior of concrete based on topological evolutionary structure optimization (ESO)
}

\section{Modelo de bielas e tirantes para comportamentos linear e não linear do concreto com base na Otimização Estrutural Evolucionária (ESO)}
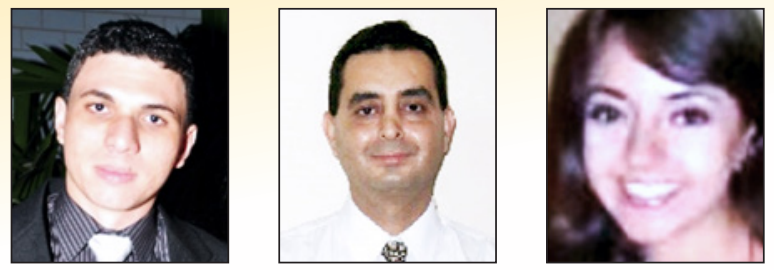

R. M. LANES a

rmlanes@yahoo.com.br https://orcid.org/ 0000-0001-7322-6869

M. GRECO a

mgreco@dees.ufmg.br https://orcid.org/ 0000-0001-5500-0225

M. B. B. F. GUERRA a

marcelabbfguerra@gmail.com https://orcid.org/ 0000-0002-9770-1588

\begin{abstract}
The search for representative resistant systems for a concrete structure requires deep knowledge about its mechanical behavior. Strut-and-tie models are classic analysis procedures to the design of reinforced concrete regions where there are stress concentrations, the so-called discontinuous regions of the structure. However, this model is strongly dependent of designer's experience regarding the compatibility between the internal flow of loads, the material's behavior, the geometry and boundary conditions. In this context, the present work has the objective of presenting the application of the strut-and-tie method in linear and non-linear on some typical structural elements, using the Evolutionary Topological Optimization Method (ESO). This optimization method considers the progressive reduction of stiffness with the removal of elements with low values of stresses. The equivalent truss system resulting from the analysis may provide greater safety and reliability.
\end{abstract}

Keywords: reinforced concrete, strut-and-tie models, Abaqus, FEM, ESO.

\section{Resumo}

A busca por sistemas resistentes representativos para estrutura de concreto requer profundo conhecimento sobre seu comportamento mecânico. Os modelos de bielas e tirantes são procedimentos clássicos utilizados no dimensionamento do concreto armado onde existem concentrações de tensão, as chamadas regiões descontínuas da estrutura. No entanto, esse modelo é fortemente dependente da experiência do analista em relação à compatibilidade entre esforços internos, comportamento do material, geometria e condições de contorno. Neste contexto, o presente trabalho tem como objetivo apresentar a aplicação de métodos de bielas e tirantes para análises linear e não-linear em alguns elementos estruturais típicos, utilizando o Método de Otimização Estrutural Evolucionária (ESO). Esse algoritmo de otimização topológica considera a redução progressiva da rigidez com a remoção de elementos com baixos valores de tensões. O sistema de treliça equivalente resultante da análise pode fornecer maior segurança e confiabilidade.

Palavras-chave: concreto armado, modelo de bielas e tirantes, Abaqus, MEF, ESO. 


\section{Introduction}

In projects' routine, it is necessary to design the components of a structure based on classic theories that describe the mechanical elements' behavior. In general, these theories present an analytical or empirical bias and knowledge about the limit of the application for each of the considered premises is fundamental to ensure the safety and the quality of the project. In the reinforced concrete design, the structure can be divided in two different regions, one governed by Bernoulli-Euler kinematic hypotheses and another governed by the principle of Saint-Venant. It allows the adequate determination of internal forces and the necessary steel for the reinforced concrete. Concrete regions in which the Bernoulli-Euler hypotheses are valid are known in the literature as B-Regions, while D-Regions correspond to regions where the Saint-Venant principle should be applied. This latter region represents a discontinuity area of the structure, distinguished as a static discontinuity (e.g., in support regions), or a geometric discontinuity (e.g., parts with abrupt changes of geometry).

The discontinuous regions of reinforced concrete can be adequately represented by the use of strut-and-tie model. This model consists on the simulation of the parts effectively loaded inside the structure by the idealization of a truss with equivalent mechanical behavior. The methodology is used for the determination of internal forces in the struts (compressed elements of the truss) and in the ties (tensioned elements of the truss).

\subsection{Justification}

The load supported by the strut-and-tie model must be evaluated by a criterion of ultimate load and, usually, it requires from the designer the experience to choose and placement of elements that defines the equivalent truss. Some normative codes propose standard strutand-tie models for some specific elements, e.g., CEB-FIP Model Code [10], CSA-A23.3-04 [7], ACl-318 [4] and [5], EUROCODE 2 [9] and ABNT NBR 6118 [6] . However, due to the clear dependence of such models with some parameters related to geometry, their applications become very limited in structural designs routine.

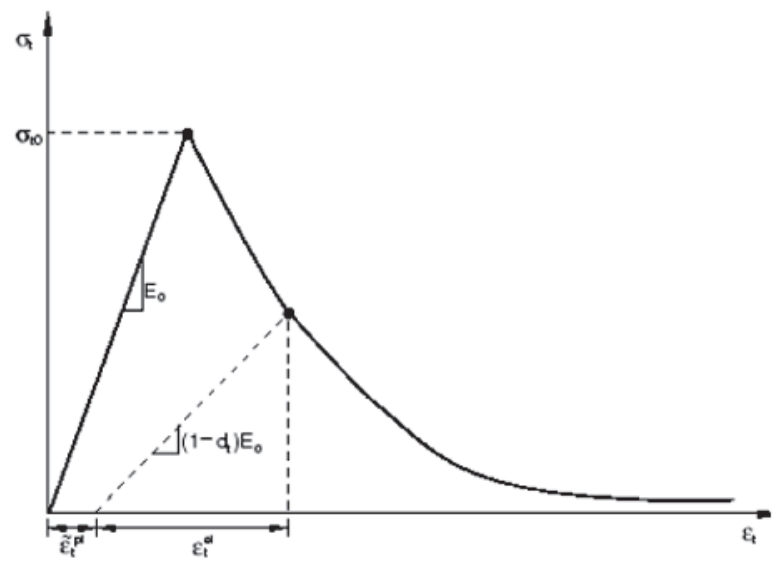

(a)
In this context, topological optimization of structures has been frequently used in structural systems assembly in D-Regions of structures in reinforced concrete [12]. The optimized design for structural models is attractive because it allows the design of trusses that tend to exhibit minimal deformation energy, or maximum stiffness, and reduces the empiricism associated with the bar systems assembly. The Evolutionary Structural Optimization (ESO) method developed by Xie and Steven ([25], [26], [27]) and Chu et al. [8] can been used to optimize continuous structures from the Finite Element Method (FEM) simulation. The ESO formulation was originally developed from an evolutionary algorithm based on a very simple concept that is based on the insertion of voids, that presents fundamentals in the gradual elements' elimination of the model that are less requested (with low level of stresses) of the domain during the process, called a hard-kill procedure. The mathematical representation of the ESO for the problems' solution for topological optimization can presented based on two concepts: stresses or displacements [16].

Since its beginning, the ESO has stood out for being a simple algorithm and for providing an easy insertion in a computational code of the FEM, without additional complex mathematical manipulations. High-performance commercial software enables ESO use in programming platforms, enabling studies for current and future research, as well as favoring the practical application in structural projects.

Therefore, the current article presents some results achieved through a structural topological analysis, via the ESO topological optimization method, implemented by Python programming script in the Abaqus $^{\circledR}$ software for analyzing multiphysical problem.

\section{Constitutive model for elastic and plastic damage}

The analysis performed in this study consider both material behaviors, the linear elastic and the non-linear. The constitutive model of plastic damage available in Abaqus ${ }^{\circledR}$ software, called CDP (Concrete Damaged Plasticity) has been adopted in the present study, for the nonlinear analysis of the elements in concrete reinforced by FEM. Initially, Lubliner [17] has proposed this model and, later,

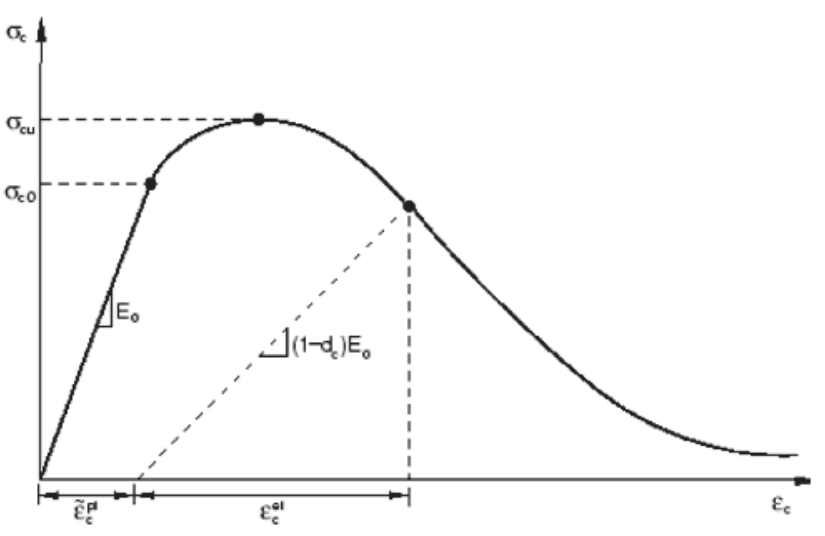

(b)

Figure 1

Concrete responses for uniaxial loading (a) in tension (b) in compression [1] 


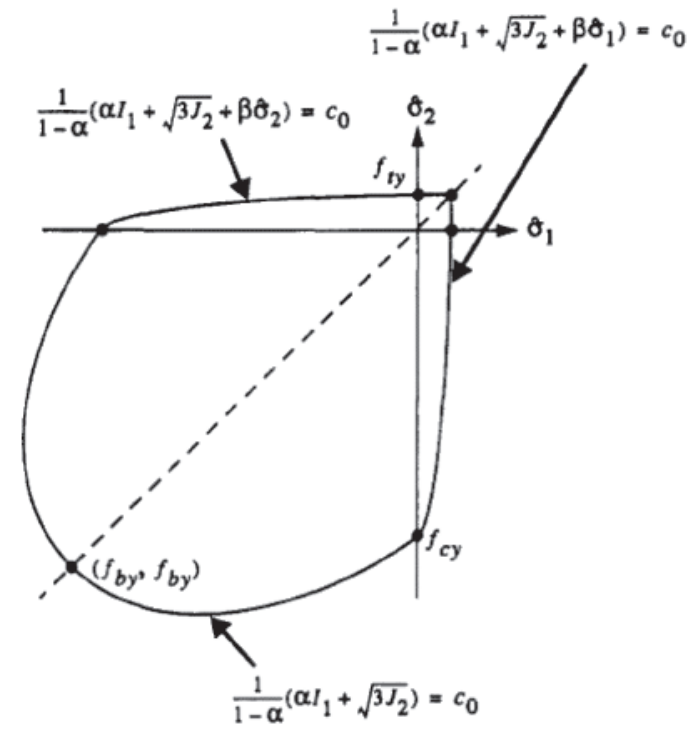

Figure 2

Surface rupture in the plane of stresses [13]

Lee and Fenves [13] suggested the modifications to simulate the multiaxial stress behavior of the concrete.

The material's behavior in linear elastic regime can be represented by Equation 2.1, according to the general Hooke law.

$\sigma=\mathrm{C} . \varepsilon$

Where $\sigma$ is the stress tensor, $\varepsilon$ is the strain tensor and $C$ is the fourthorder constitutive tensor. For nonlinear behavior of plastic damage in the uniaxial case of stresses, stress-strain relationships are governed by scalar elastic damage, as noticed in the Equation 2.2.

$\sigma=(1-\mathrm{d}) \cdot E_{0} \cdot\left(\epsilon^{e}-\check{\epsilon}^{p l}\right)$

Being $E_{0}$ equal the initial elastic Young's modulus and (1-d) $E_{0}$ equal the effective plastic Young's modulus. The $d$ parameter represents the scalar plastic damage variable (ratio of damaged area to total cross-sectional area) for isotropic damage, 0 (zero) for nondamaged material and 1 (one) for completely damaged material $(0 \leq \mathrm{d} \leq 1)$, while $\left(\epsilon^{e}-\breve{\epsilon}^{p l}\right)$ means the plastic tensor strain. It is worthy of notice that the evolution of the rupture on surface is controlled by two variables, related to damaging mechanisms due to the loss of tensile strength and compression strength, respectively. Both are characterized, independently, as shown in Figure 1.

The failure surface is represented by the following equation (2.3), due to the stress and the plastic damage variable.

$f\left(\sigma, \bar{d}_{p}\right)=\frac{1}{1-\alpha}\left[\alpha \cdot I_{1}+\sqrt{3 \cdot J_{2}}+\beta \cdot\left(\bar{d}_{p}\right) \cdot\left(\sigma_{\text {máx }}\right)-c_{c^{\prime}} \cdot\left(\bar{d}_{p}\right)\right]$

where $\alpha, \beta$ are the non-dimensional constants of the material, $I_{1}$ is the first stress invariant, $J_{2}$ being the second principal invariant of the deviatoric stress, $\sigma_{\max }$ is the maximum algebraic value of the principal stress, $\mathrm{C}_{\mathrm{c}}$ is the cohesion variable for compression and, finally, $\bar{d}_{p}=\left|\begin{array}{l}d_{p t} \\ d_{p c}\end{array}\right|$ is the vector plastic damage variable represented by two components, one for tension and other for compression.

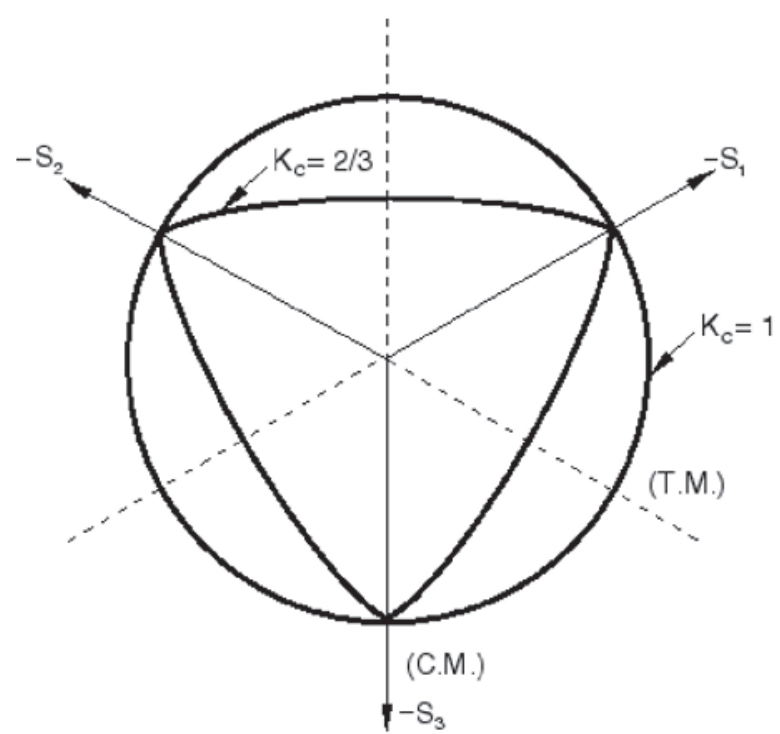

Figure 3

Corresponding values for the parameter [13]

The Figure 2 shows the failure surface in the plane stress.

The rule of the plastic yielding allows determining the strains' evolution in the structure from increments of plastic deformation, as the load is applied, and these strains are obtained by means of the derivative of a potential function $(G)$.

The $G$ potential function is a scalar function of stress tensor and the increments of plastic deformation can be determined by partial derivatives with respect to the components of the stress tensor.

$d \epsilon_{i j}^{p l}=d \gamma \cdot \frac{d G}{d \sigma_{i j}}$

where $d \gamma$ is the constant of proportionality greater than zero, denominated plastic multiplier. The potential plastic function, in the constitutive model adopted, is defined in the space of the effective stresses from the hyperbolic function of Drucker-Prager presented in the following equation (2.5).

$G=\sqrt{\left(\sigma_{c 0}-e \cdot \sigma_{t 0} \tan \psi\right)^{2}+\bar{p}^{2}}-\xi \cdot \tan \psi-\sigma$

Being $\sigma_{t 0}$ and $\sigma_{c 0}$ equal the concrete tensile and compressive strength, respectively; $\psi$ is the dilation angle measured in meridional plane at high confining pressures; $e$ is the eccentricity of the plastic potential surface, which doesn't match with the yield surface, in other words, it is non-associative.

Beyond of the definition of scalar plastic damage variable (d) is necessary to define other parameters using the constitutive model in the Abaqus ${ }^{\circledR}$ software. They are presented bellow and the values adopted for the representation of the stresses' multiaxial state effects are detailed too.

- $\mathrm{K}_{\mathrm{c}}$ : ratio between the distance of the hydrostatic axis to the meridian of traction and of compression in the diverter plane, varies between 0.5 and 1.0 , with $\mathrm{K}_{\mathrm{c}}=2 / 3$ being the most adopted. When it assumes the value equal to 1 (one), the cross-section of the failure surface in the anti-spherical plane is in the form of a circle, as in the classical Drucker-Prager criterion, as shown in Figure 3; 


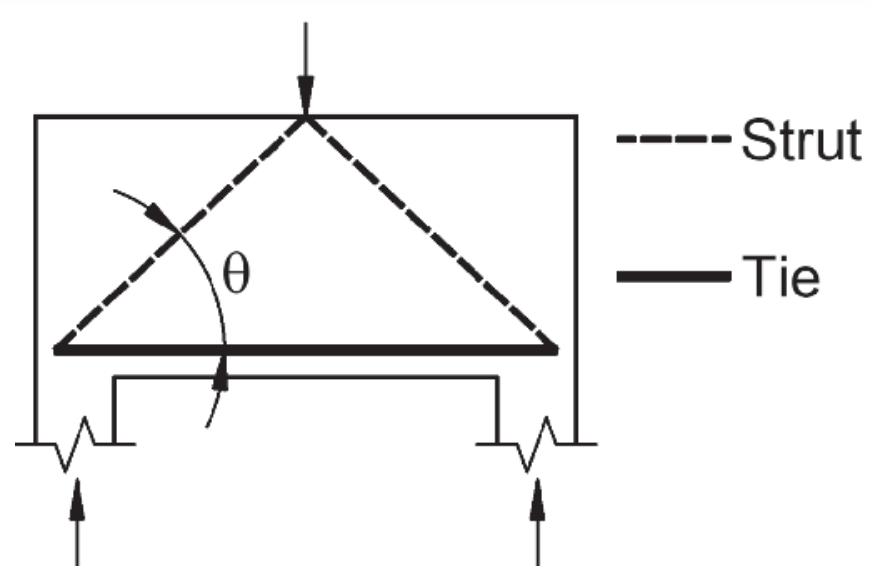

Figure 4

Strut-and-tie models according to Silva and Giongo (adapted from [24])

- Plastic potential eccentricity (e): value comprised between $0 \leq$ and $\leq 1$. When it assumes the value equal to zero, the surface in the meridional plane becomes a straight line, that is, the classic criterion of Drucker-Prager.

- Ratio $f_{b c} / f_{c}$ : such parameter can be obtained by the relationship of tensile and compressive strengths. The value generally adopted is around 1.16;

- Angle of Dilation $(\psi)$ : the angle that will describe the slope of the rupture surface in related to hydrostatic axis. The dilatation angle can be interpreted physically as an angle of internal friction of the concrete, generally adopted being equal to $36^{\circ}$ or $40^{\circ}$;

- Viscosity parameter $(\mu)$ : necessary to regularize the constitutive equations. According to Kmiecik and Kamiński [11], the viscoplastic adjustment consists in the choice of " $\mu$ " greater than zero, sometimes being necessary to adjust this value in order to find out the influence of the parameter on the result and what the value least suitable for the problem.

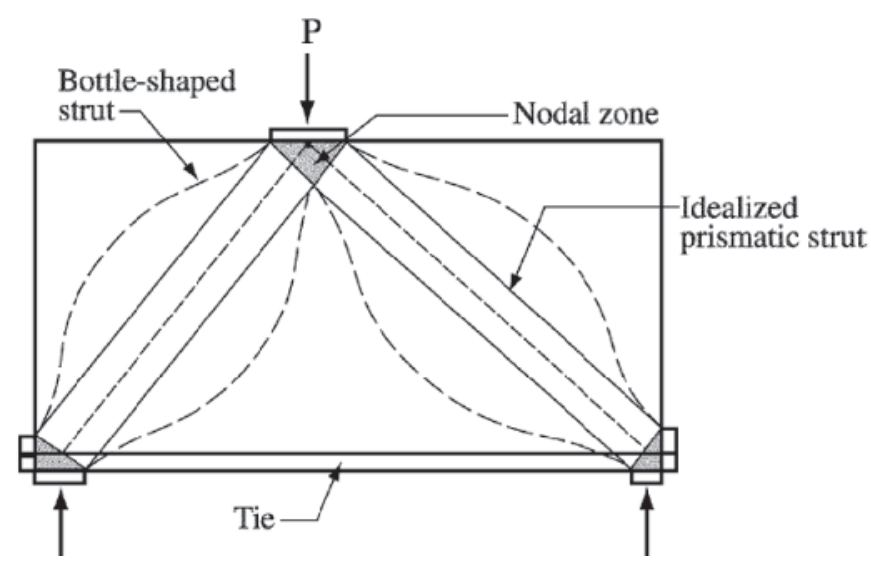

\section{Figure 5}

Strut-and-tie Model of a simply supported beam ([5] and [18])

\section{Definition of the struts-and-tie model}

According to Silva and Giongo [24], the main aspects to be considered for the strut-and-tie model geometry definition are the types of actions that are developed in the element, the angle between the strut and the tie and the boundary conditions which also includes the number of layers of the reinforcement and its cover.

Silva and Giongo [24] also explain that when defining the model it is important to provide a satisfactory space for the struts-and-tie in such a way that the angles $\theta$ between these elements do not get too small. Several researchers and some normative codes set limits to the values of these angles. Figure 4 illustrates the model according to Silva and Giongo [24].

MacGregor [18] points out that the struts-and-ties must be arranged in a way that there is a coincidence between the centers of gravity of each element and the lines of action of external forces acting on each node. Figure 5 sketches a beam with its respective arrangement of model elements, struts, ties and nodal zones where the transfer of forces will occur.

Wight and Macgregor [18] claim that a strut-and-tie model must satisfy some criteria, among which the internal stress equilibrium, considering a given set of loads, which must not exceed limits in relation to the actual resistance of the structure. This theory corresponds to the Plasticity Lower Limit Theorem.

Schäfer and Schlaich ([22] and [23]) also indicate such behavior analyzes of the element considering the ultimate limit in the elastic state, to define the strut-and-tie model topology, and the plastic state, to design the structure.

Some commonly adopted criteria for choosing the strut-and-tie model are mentioned in the literature, e.g., those prescribed in normative codes, the criterion adopted by the "Load Path Approach", from elastic analyzes by FEM, from nonlinear analyzes with the considering the concrete cracking, by means of experimental tests and by means of numeric models.

\section{ABNT NBR 6118 recommendations}

The Brazilian design code ABNT NBR 6118:2014 [6] determines limit values for the struts in the analysis of compression stresses between the nodal regions. The steel reinforcements totally supports the traction in ties.

Both design criteria is summarized in the following items.

\subsection{Design of struts}

The stresses in the struts should not exceed the values obtained from equations 4.1 to 4.3 .

For nodal regions with only struts (CCC nodes):

$\mathrm{F}_{\mathrm{cd} 1}=0,85 \alpha_{\mathrm{v} 2} \mathrm{f}_{\mathrm{cd}}$

- For nodal regions with one tie (CCT nodes):

$\mathrm{F}_{\mathrm{cd} 3}=0,72 \alpha_{\mathrm{v} 2} \mathrm{f}_{\mathrm{cd}}$

For nodal regions with two or more ties (CTT or TTT nodes):

$\mathrm{F}_{\mathrm{cd} 2}=0,60 \alpha_{\mathrm{v} 2} \mathrm{f}_{\mathrm{cd}}$ 
where:

$\alpha_{v 2}=1-f_{c k} / 250$, with fck being the characteristic compressive strength of the concrete expressed in MPa and;

$f_{c d}$ is the concrete compressive strength, being equal to $f_{c k} / \gamma_{c}$. The parameter $\gamma_{c}$ is the concrete reduction factor strength.

\subsection{Design of ties}

According to Brazilian design code ABNT NBR 6118:2014 [6], the resultant reinforcement area to be applied for each tie is given by Equation 4.4.

$\mathrm{A}_{\mathrm{s}}=\frac{F_{\text {sd }}}{\mathrm{f}_{\mathrm{yd}}}$

where:

$\mathrm{F}_{\text {sd }}$ is the design tie force and;

$f_{y d}$ is the design reinforcement yield strength.

\section{Evolutionary structural optimization (ESO) algorithm}

According to Liang et al. [16], the optimization of continuous structures subject to stress constraints may be expressed as follows Equation 5.1.

minimize $=\sum_{\mathrm{e}=1}^{\mathrm{N}} \mathrm{w}_{\mathrm{e}}\left(\mathrm{t}_{\mathrm{e}}\right)$

restriction $=\sigma_{\max }^{\mathrm{VM}} \leq \sigma^{*}$

Where $w_{e}$ is the weight of the nth element; $t$ is the thickness of the $n_{\text {th }}$ element; and $\sigma{ }^{*}$ is the prescribed limit stress. Thus, the reduction of the mass is carried out from the criterion of maximum stress in the structure, in which the elements with smaller values of stress in the whole structure are selected and disregarded in the mesh (Figure 6).

This removal criterion, initially proposed by Xie and Steven in [25], is described by Inequation (5.2) as follows:

$\sigma_{\mathrm{e}}^{\mathrm{vM}}<R R_{\mathrm{i}} \cdot \sigma_{\mathrm{MAX}}^{\mathrm{VM}}$

where $\sigma_{\mathrm{e}}^{\mathrm{vM}}$ is the equivalent von Mises stress (scalar value) in the analyzed element; $R R \_i$ is the rejection ratio adopted to delay the removal process with the following variation $0<R R_{i}<1,0$ and $\sigma_{\mathrm{MAX}}^{\mathrm{VM}}$ is the maximum von Mises stress of the iteration.

From that point, it is possible to say that the removal cycle of elements will occur until no more elements can be removed at a given RRi value. However, when reaching this level of equilibrium, without achieving the optimum configuration, the evolutionary process would be redefined by adding $R R_{i}$ and $E R$ evolution ratio. A new cycle of evolution would begin until there are no more elements to be eliminated with this new rejection ratio. However, (though) once the equilibrium is reached again, the rejection ratio $\left(R R_{i}\right)$ is again updated. Equation (5.3) describes this process.

$\mathrm{RR}_{\mathrm{i}+1}=\mathrm{RR}_{\mathrm{i}}+\mathrm{ER} \quad \mathrm{i}=0,1,2, \ldots$

The initial value of the rejection ratio $\left(R R_{i}\right)$ is defined empirically according to the user experience for each type of problem. The guarantee of the best convergence is given considering small values for the rate of evolution (ER) and rejection ratio $\left(R R_{i}\right)$ around $1 \%$, preventing the removal of a very large region from the domain [20].

The RR will be updated until an optimized configuration is reached or after reaching a required stop criterion. The stopping criterion may be a final volume prescribed for the structure or a final rejection ratio. Thus, the removal ratio of the iteration must always be less than a pre-established maximum removal ratio $R_{\mathrm{f}}$.

The equivalent von Mises stress for a plane-stress is getting from the Equation 5.4:

$\sigma_{\mathrm{e}}^{\mathrm{vM}}=\sqrt{\sigma_{11}^{2}-\sigma_{11} \sigma_{22}+\sigma_{22}^{2}+3 \tau_{12}}$

With $\sigma_{11}$ and $\sigma_{22}$ equal the normal components of the tension in the respective $x$ and $y$ directions; $\tau_{12}$ equal the shear stress components. A script was developed from a high-level programming language Phyton with the aim of automating the analysis of topological optimization in structural elements using Abaqus ${ }^{\circledR}$ software. The evolutionary process adopted to implement the computational code is summarized by the following steps:

a) Step 1: discretization of the initial domain of the structure, using a fine mesh of finite elements, and application of boundary conditions and prescribed actions;

b) Step 2: analyze the structure by finite elements (linear and non-linear behavior);

c) Step 3: remove the elements that satisfy the Inequation (5.2);

d) Step 4: Increase the rejection ratio according to Equation (5.3) until equilibrium is reached otherwise repeat steps 2 and 3;

e) Step 5: Repeat steps 2 through 4 until the optimum design is reached.

In the developed routine, the removal of the elements in the system does not occur with the literal removal of the elements. After the identification of the less requested regions, the mechanical properties of these regions are changed to a section or a material with negligible structural characteristics when compared with its initial mechanical characteristics. Therefore, the routine requires the user to establish physical characteristics (such as low modulus of elasticity and density, among others) for the structural deactivation of the component elements of the domain.

From the topology found, the strut-and-tie models were proposed for the simulation of structural systems of D-Regions of the reinforced concrete.

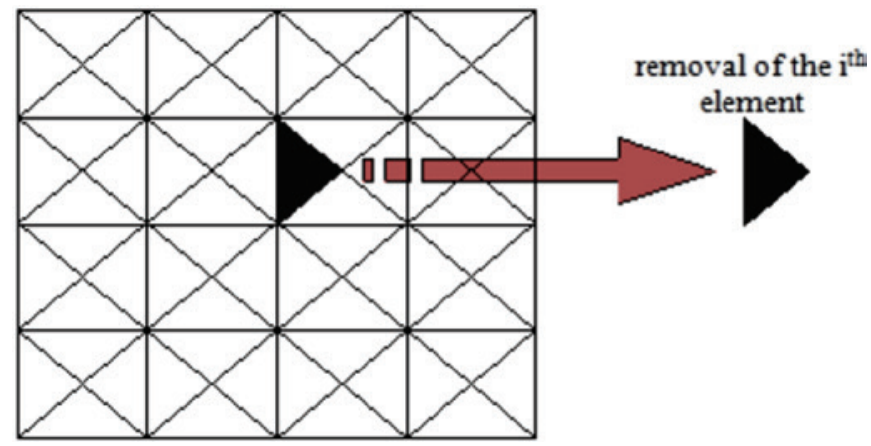

Figure 6

Removal of the element from mesh by the method of optimization [19] 


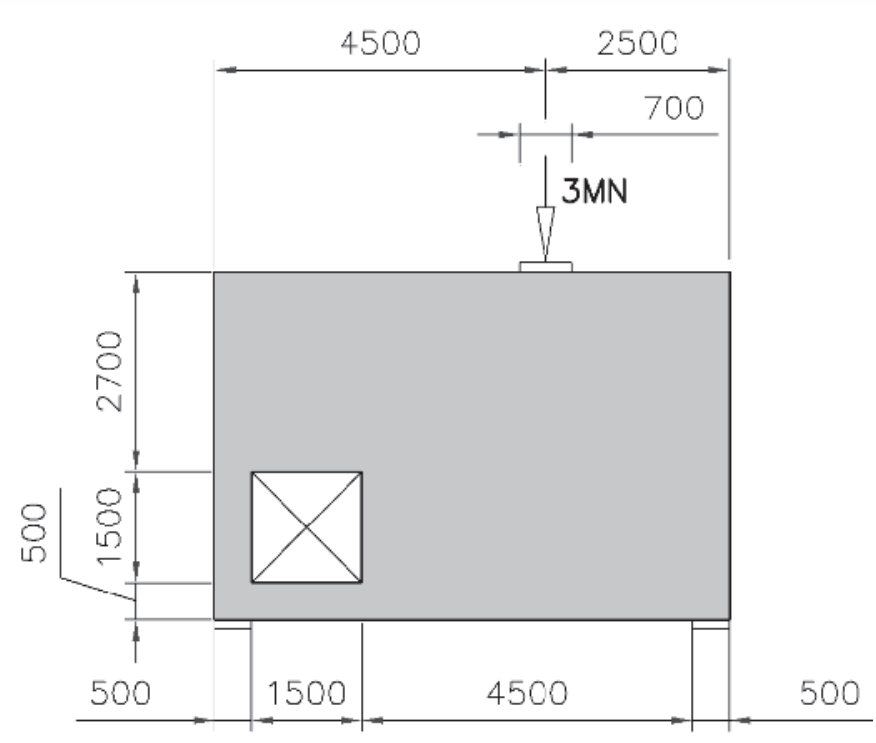

Figure 7

Simply supported deep beam with a hole [21]

\section{Numerical examples}

With the formulation described in the previous items, a computational system was developed with application of the ESO algorithm in conjunction with the finite element method. ESO was applied to obtain optimum topologies under the hypothesis of material with linear and nonlinear elastic behavior, in order to evaluate the sensitivity of the resulting strut-and-tie models. The completed structural models are considered during analyzes, that is, no symmetry condition was considered.

In the presented parameters on section 2 of this paper were adopted the same for nonlinear concrete behavior in all examples, to know:

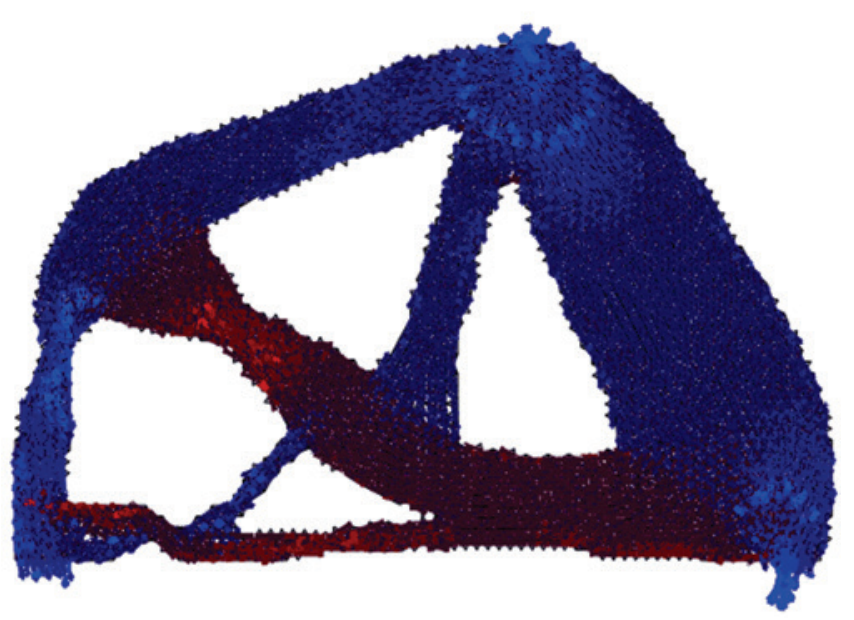

(a)
$\mathrm{K}_{\mathrm{c}}=2 / 3[1]$

- Plastic potential eccentricity $(\mathrm{e})=0.1$;

$\mathrm{f}_{\mathrm{bc}} / \mathrm{f}_{\mathrm{c}}=1.16$;

- Angle of Dilation $(\psi)=36^{\circ}$;

- Viscosity parameter $(\mu)=0.1$.

\subsection{Example 1: simply supported deep beam with a hole [21]}

The structural element is a simply supported deep beam with a hole that is loaded by single force, as detailed in Figure 7 with all geometry presented in millimeters.

The adopted properties for material were adapted from Almeida et al. [2], with beam thickness equal to $800 \mathrm{~mm}$, modulus of elasticity equal to $E=20,820 \mathrm{MPa}$, characteristic compressive strength of the concrete equal to $\mathrm{f}_{\mathrm{ck}}=28.0 \mathrm{MPa}$ and $\gamma_{\mathrm{c}}$ equal to 1.40 and, finally, Poisson coefficient equal to $v=0.15$.

For assembling purposes using Abaqus ${ }^{\circledR}$ software, a simple triangular finite element mesh CPS3 (Continuum/ Plane-Stress/3 Node Element) type was considered. The structure was represented by 6,693 elements and 3,499 nodes. The parameters used for the optimization via ESO were: Removal Factor $\left(R_{0}\right)=4.0 \%$ and the Evolution Factor $(E R)=2.0 \%$. The optimum topologies obtained with the consideration of linear and non-linear behavior of the material to a volume of approximately $50 \%$ of the initial volume are presented in Figure 8. The same figure also shows the stress distributions obtained through FEM, with the stress flows in blue color being the compression regions and the red color, the tensile regions.

It is notable that the optimum topologies found by the ESO algorithm for the concrete hypothesis with linear elastic behavior presents results very close to those found in the literature, as shown in Figure 9. This result allows us to validate the implemented optimization code and to admit that the resulting optimum topologies are very close to the expected optimum topologies, regardless the optimization method used.

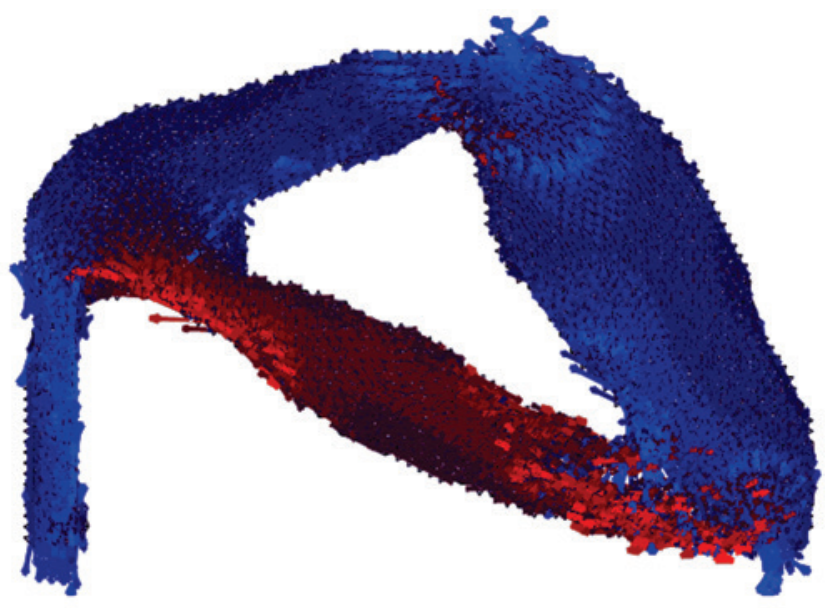

(b)

\section{Figure 8}

Optimum topologies by ESO and stress distribution obtained for the element, according to FEM (a) considering the linear and (b) non-linear behavior 


$$
\Delta
$$




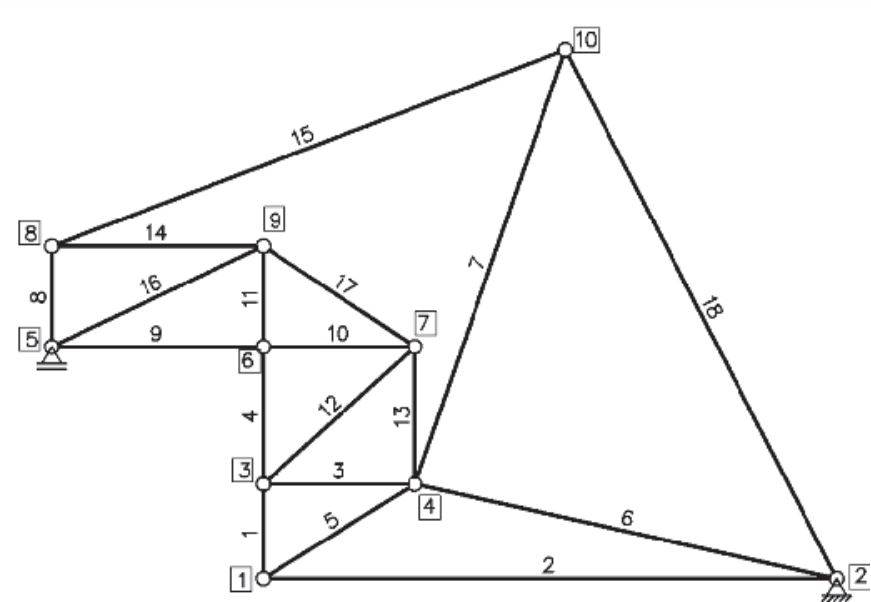

Figure 10

Strut-and-tie model with nodes and member numbers for Example 1

It should be remembered that the stopping criterion corresponds for approximately $50 \%$ of the initial volume was applied for the definition of the optimized topology in both Finite Element models and, then, the ESO procedure was used. However, it can be seen that the results obtained to the deep beam structure showed significant
Table 1

Identification of nodes of the Example 1

\begin{tabular}{cccc}
\hline Node number & $\mathbf{X}(\mathbf{m})$ & $\mathbf{Y}(\mathbf{m})$ & Type \\
\hline 1 & 1.730 & 0.000 & CTT \\
2 & 6.420 & 0.000 & $\mathrm{CTT}$ \\
3 & 1.730 & 0.770 & TाT \\
4 & 2.970 & 0.770 & TTा \\
5 & 0.000 & 1.890 & $\mathrm{CCT}$ \\
6 & 1.730 & 1.890 & TाT \\
7 & 2.970 & 1.890 & $\mathrm{CTT}$ \\
8 & 0.000 & 2.710 & $\mathrm{CCT}$ \\
9 & 1.730 & 2.710 & $\mathrm{CTT}$ \\
10 & 4.200 & 4.310 & $\mathrm{CCC}$ \\
\hline
\end{tabular}

differences between the optimum topology of a linear material and the optimum topology of a non-linear material. The optimum model selection, with minimum strain energy, or maximum stiffness, is the model represented by the largest number of bars for a truss system and, therefore, the topology indicated in Figure 8 (a). From this step, the definition of the optimized topology is interpreted to the truss, as indicated in Figure 10. The suggested strut-and-tie model corresponds to an envelope of solutions for concrete behavior, whether in a linear or non-linear regime.

In this context, the coordinates of the nodes and the axial forces

Table 2

Design of the compression bars of the Example 1

\begin{tabular}{ccccccc}
\hline $\begin{array}{c}\text { Member } \\
\text { number }\end{array}$ & $\begin{array}{c}\mathbf{F}_{\text {sd }} \\
(\mathbf{k N})\end{array}$ & $\begin{array}{c}\mathbf{A} \\
\left(\mathbf{c m}^{2}\right)\end{array}$ & $\begin{array}{c}\sigma_{\mathrm{c}} \\
(\mathbf{M P a})\end{array}$ & $\begin{array}{c}\mathbf{F}_{\text {cd }} \\
(\mathbf{M P a})\end{array}$ & Criterion & Conclusion \\
\hline 5 & -670 & 3,706 & 1.81 & 10.66 & $T T$ & Ok \\
7 & -633 & 5,288 & 1.20 & 10.66 & $\pi T$ & Ok \\
8 & -328 & 4,000 & 0.82 & 12.79 & $\mathrm{CCT}$ & Ok \\
12 & $-1,160$ & 1,583 & 7.32 & 10.66 & $T \pi$ & Ok \\
15 & -921 & 2,000 & 4.60 & 12.79 & $\mathrm{CCT}$ & Ok \\
16 & $-1,657$ & 1,704 & 9.72 & 10.66 & $\mathrm{CT}$ & Ok \\
17 & -763 & 1,294 & 5.90 & 10.66 & $\mathrm{CTT}$ & Ok \\
18 & $-2,333$ & 3,560 & 6.55 & 10.66 & $\mathrm{CTT}$ & Ok \\
\hline
\end{tabular}

Table 3

Characteristics of the footings

\begin{tabular}{cccccc}
\hline $\begin{array}{c}\text { Member } \\
\text { number }\end{array}$ & $\begin{array}{c}\mathbf{F}_{\text {sd }} \\
(\mathrm{kN})\end{array}$ & $\begin{array}{c}\text { Angle between } \\
\text { horizontal } \\
\text { direction and the } \\
\text { member }\left({ }^{\circ}\right)\end{array}$ & $\begin{array}{c}\mathbf{A}_{\mathrm{s}} \\
\left(\mathrm{cm}^{2}\right)\end{array}$ & $\begin{array}{c}\mathbf{A}_{\mathrm{sx}} \\
\left(\mathrm{cm}^{2}\right)\end{array}$ & $\begin{array}{c}\mathbf{A}_{\text {sy }} \\
\left(\mathrm{cm}^{2}\right)\end{array}$ \\
\hline 1 & 353 & 90.0 & 8.1 & 0.0 & 8.1 \\
2 & 569 & 0.0 & 13.1 & 13.1 & 0.0 \\
3 & 861 & 0.0 & 19.8 & 19.8 & 0.0 \\
4 & 1,131 & 90.0 & 26.0 & 0.0 & 26.0 \\
6 & 512 & 12.6 & 11.8 & 12.1 & 0.0 \\
9 & 1,497 & 0.0 & 34.4 & 34.4 & 0.0 \\
10 & 1,497 & 0.0 & 34.4 & 34.4 & 0.0 \\
11 & 1,131 & 90.0 & 26.0 & 0.0 & 26.0 \\
13 & 356 & 90.0 & 8.2 & 0.0 & 8.2 \\
14 & 861 & 0.0 & 19.8 & 19.8 & 0.0 \\
\hline
\end{tabular}




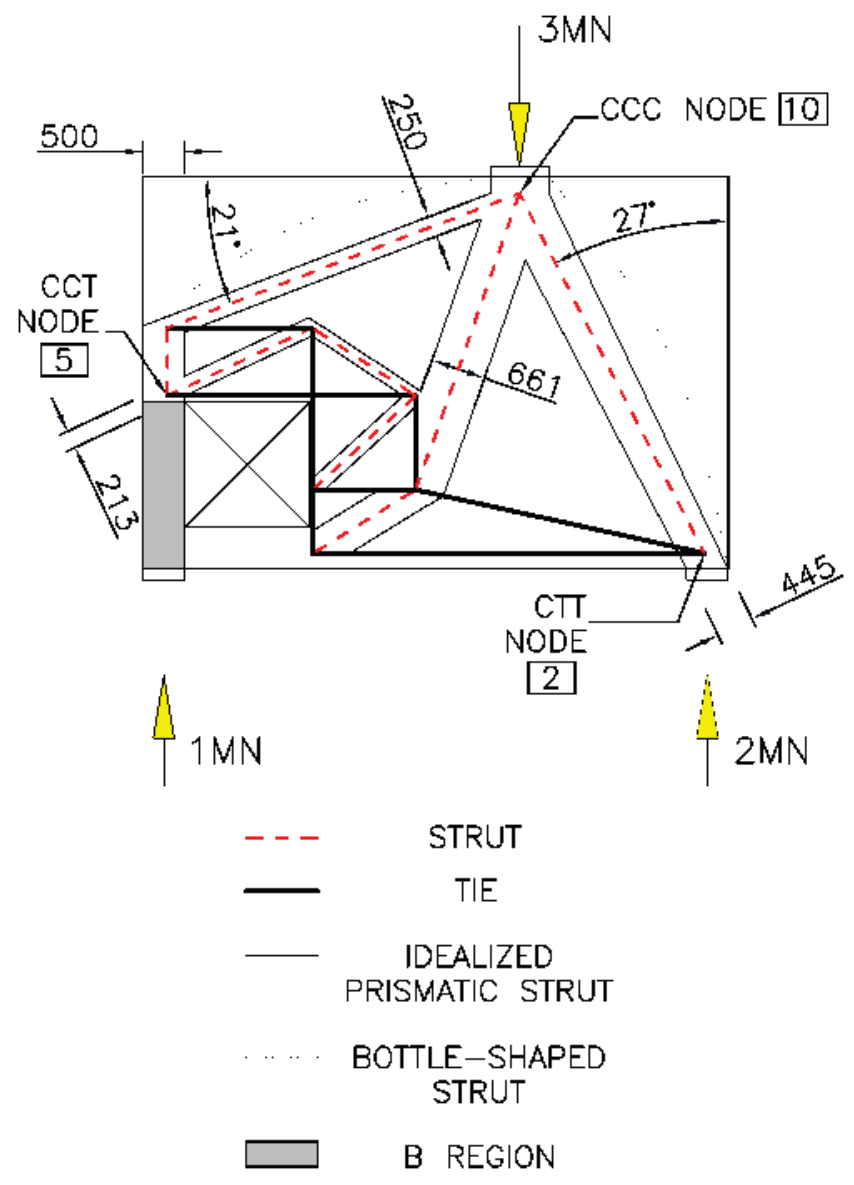

Figure 11

Geometry of strut for Example 1

obtained in the structural analysis of idealized truss are presented in tables 1 to 3 and the Figure 12 presents a project sketch of reinforcement concrete in the proposed model. The rebars' design was based on the Brazilian standard [6] and the steel considered was the CA50, as shown in detail on the next sub items for struts-andties design on the example.

\subsubsection{Design of struts}

To design the compressed bars, the struts, of a simply supported deep beam with a hole shown in Figure 7, it is necessary to identify the truss nodal points, as it is presented on Table 1. As mentioned in Chapter 4.1, these points can be labeled as the CCC, CCT, CTT or TTT node. The Figure 11 shows some dimension of struts in millimeters and the category of the labeled nodes 2, 5 and 10 . All of the compression strength resistance verifications for each compressed bar is presented in Table 2 and the strength resistance of the compressed bar must be ensured for both extreme nodes that are connected to the element under analysis.

The A symbol represents the cross section area of compression bars and it is determined by trigonometry or graphical analysis for each strut, as shown for a few in Figure 11. The compressive stress $\sigma_{c}$ is obtained by the ratio between $F_{s d}$ and $A$ for all of the bars and, in addition, each compression stress is compared with $F_{c d 1}, F_{c d 2}$ or $F_{c d 3}$ concrete strength in the node region, as presented in Chapter 4.1. In Table 2, the $F_{c d}$ means the $F_{c d 1}, F_{c d 2}$ or $F_{c d 3}$, which depends of each criterion shown in column number 6 of the same table. Therefore, it can be concluded that all struts for the idealized truss system on Example 1 support the design compressive stresses caused by the concentrated load of 3.0 MN shown in Figure 7.

\subsubsection{Design of ties}

To design the traction bars, or the ties, of a simply supported deep beam with a hole shown in Figure 7, it is necessary to use the Equation 4.4. This equation provides the steel reinforcement cross

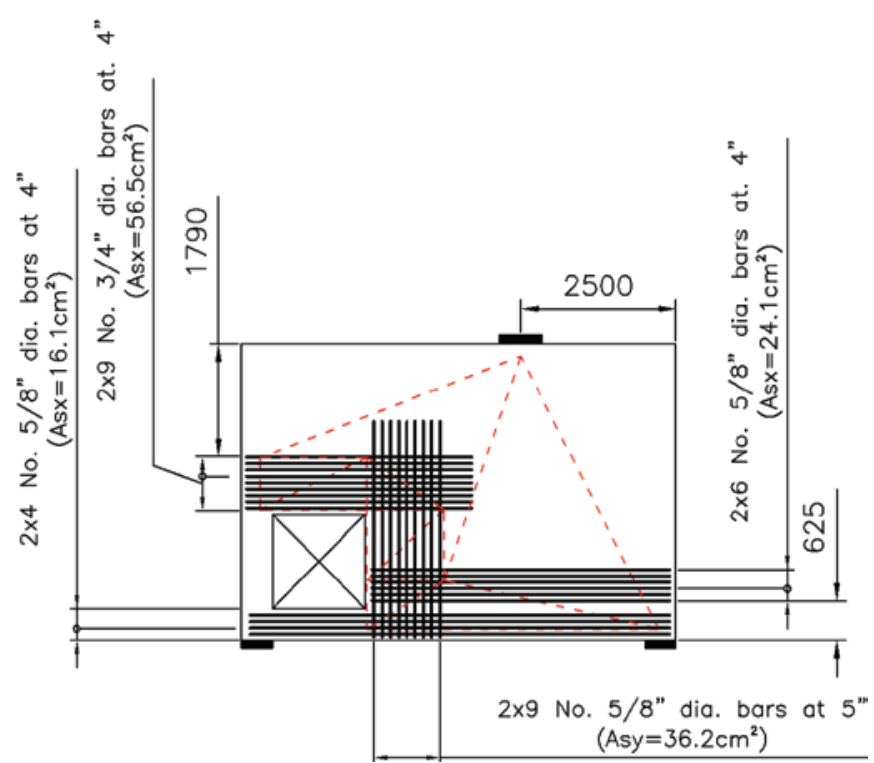

Figure 12

Reinforcement sketch for Example 1

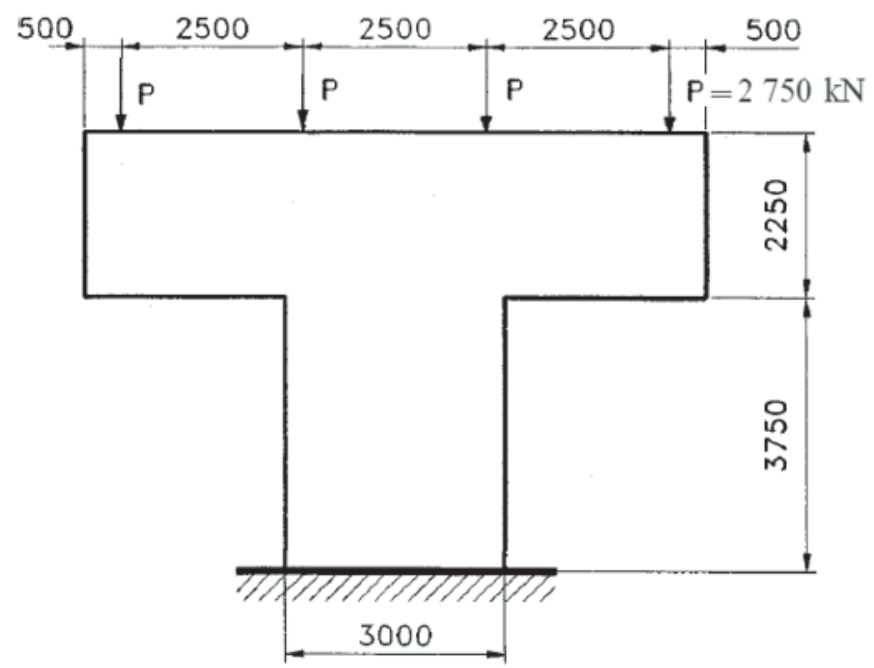

Figure 13

Bridge column [15] 


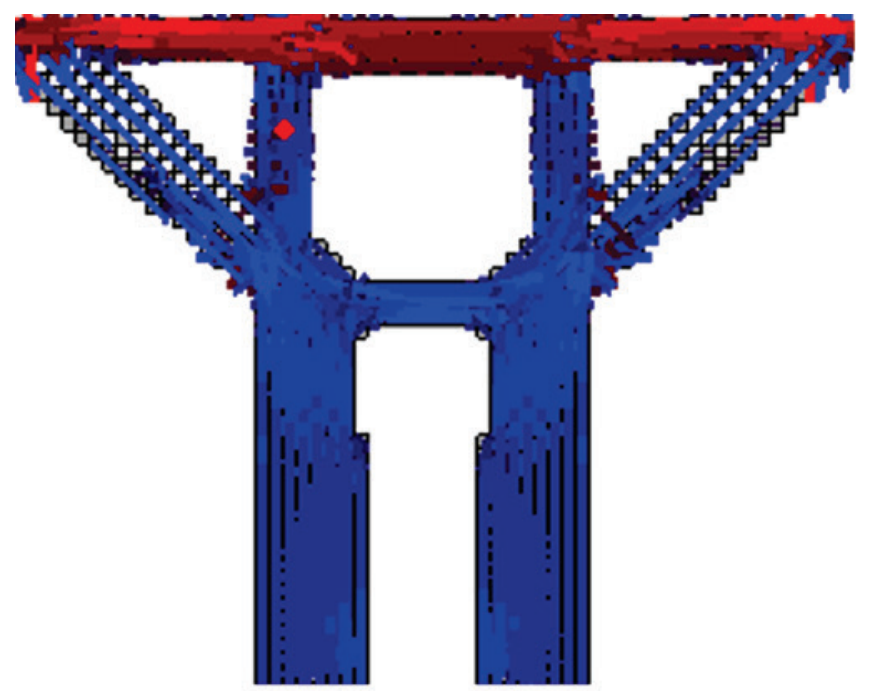

(a)

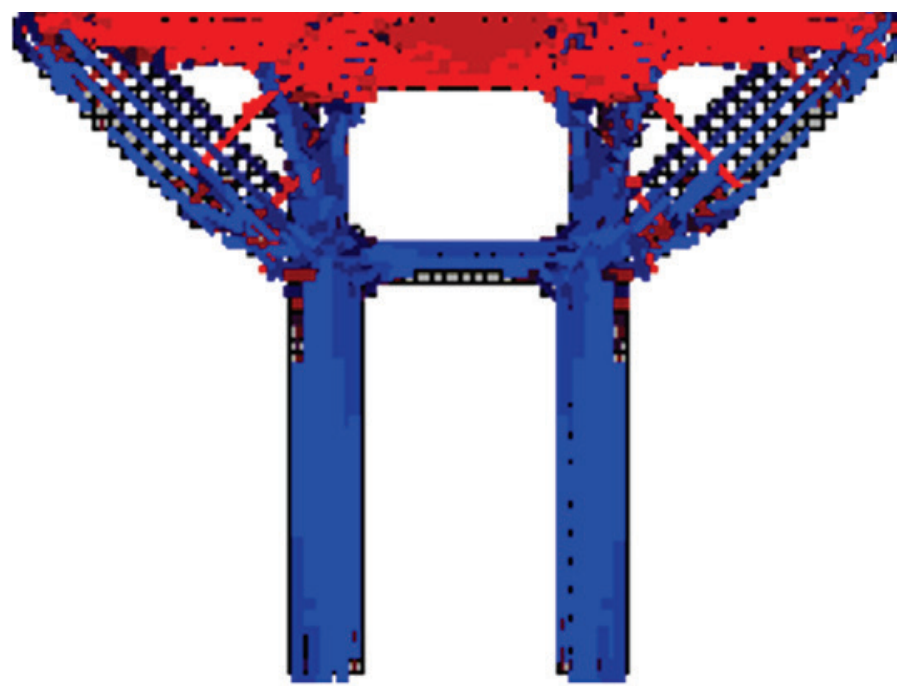

(b)

Figure 14

Optimum topologies by ESO and stress distribution required for the element, according to FEM (a) for linear and (b) non-linear behavior

sectional area that is required for equilibrium purposes of idealized truss system. In principle, that reinforcement should be applied at the same position associated to the truss tie. However, for constructive reasons, it is usually interesting that rebars are arranged at horizontal and vertical directions. Independently of the rebar position, reinforcement concrete design needs to respect the required strength at the direction of each traction bar of truss idealized system.

The Table 3 presents the steel reinforcing cross section area determined for all traction bars in parallel direction $\left(A_{s}\right)$, horizontal direction $\left(A_{s x}\right)$ and in vertical direction $\left(A_{s y}\right)$ for truss idealized

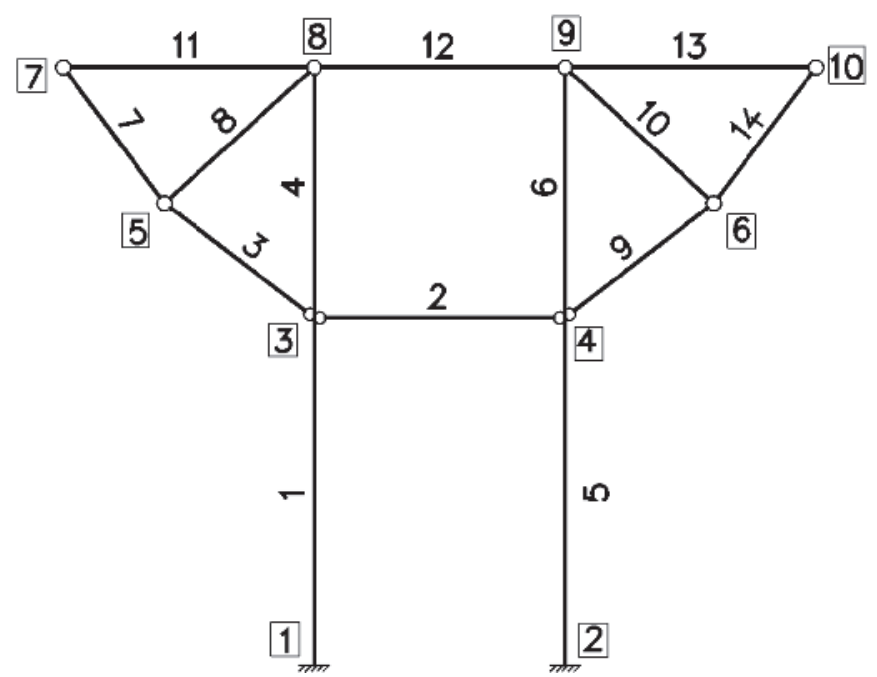

Figure 15

Strut-and-tie model with nodes and member numbers for Example 2 system. Figure 12 presents a sketch of the rebars' design for the structure on Example 1, after knowing all the required steel reinforcing cross section area in horizontal and vertical direction for each traction bar.

\subsection{Example 2: bridge column [14]}

The structural element is a bridge column that is loaded by four equal forces $P$, as detailed in Figure 13. The thickness of structure is $1.50 \mathrm{~m}$ and the properties adopted for the material were the same as those reported in Liang et al. [14], with the modulus of elasticity equal to $\mathrm{E}=28,600 \mathrm{MPa}$, characteristic compressive strength of the concrete equal to $f_{c k}=28.0$ $\mathrm{MPa}$ and $\gamma_{\mathrm{c}}$ equal to 1.40 , and, finally, the Poisson's coefficient equal to $v=0.15$. The shown dimensions are expressed in millimeters.

To assembly the elements in Abaqus ${ }^{\circledR}$ software, a triangular linear finite element mesh CPS4R (Continuum / Plane-Stress / Shell elements / 4 Node Element) type was considered. The structure was represented by 1,944 elements and 2,061 nodes. For this case, it was considered symmetry in the finite element mesh generation. The parameters used for ESO optimization were: Removal Factor $(\mathrm{RR})=4.0 \%$ and Evolution Factor $(E R)=2.0 \%$. The optimum topology was obtained from a volume of approximately $50 \%$ of the initial volume. The solutions, considering the elastic and non-linear behavior of the material, are presented in Figure 14. The same figure also shows the stress distributions obtained through FEM and the stress flows in the blue color being the compression regions and in the red, the tensile regions.

For the studied example, it may be observed that differences between the obtained topology for the linear material and the obtained topology for non-linear material were relatively small. The results interpretation of a structural model with strut-and-tie 
Table 4

Identification of nodes of the Example 2

\begin{tabular}{cccc}
\hline Node number & $\mathbf{X}(\mathbf{m})$ & $\mathbf{Y}(\mathbf{m})$ & Type \\
\hline 1 & 10,000 & 0,000 & CCC \\
2 & 12,500 & 0,000 & CCC \\
3 & 10,000 & 3,450 & CCC \\
4 & 12,500 & 3,450 & CCC \\
5 & 8,510 & 4,590 & CCT \\
6 & 13,980 & 4,590 & CCT \\
7 & 7,500 & 5,940 & CCT \\
8 & 10,000 & 5,940 & TTा \\
9 & 12,500 & 5,940 & TTा \\
10 & 15,000 & 5,940 & CCT \\
\hline
\end{tabular}

presents irrelevant differences in the concept of truss structural system. The result suggests that such response is very close to a global optimum geometry for the structure, either for the linear or nonlinear regime. The optimum model selection, with minimum strain energy, or maximum stiffness, is the model represented by the largest number of bars for the truss and, therefore, the topology indicated in Figure 14(b). From this step, the definition of optimized topology is interpreted for the structure, as shown in Figure 15.

As shown in Liang et al. [14], in order to simplify the solution of truss system, the compressed diagonals can be connected to the compressed horizontal bar in the same node of final topology indicated in Figure 14(b). The procedure subtly adjusts the column length of the bridge until the bottom face of the beam. To not modify in a significantly way, the solution presented in the literature, the procedure was also adopted for this paper. Thus, the nodes' coordinates and the axial forces obtained in the structural analysis of the idealized truss of Example 2 are presented in Table 4.

In this context, the suggested strut-and-tie model corresponds to an envelope of solutions for possible concrete behaviors, either in linear or non-linear regime. Figure 16 presents a project sketch of reinforcement concrete in the proposed model. The design of reinforcement was based on the Brazilian standard [6] and the considered steel was the CA50.

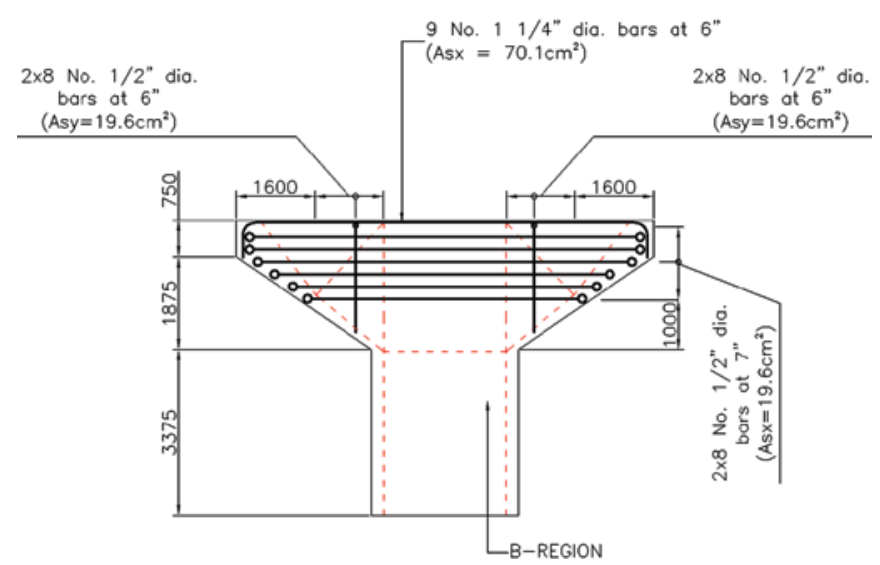

Figure 16

Reinforcement sketch for Example 2

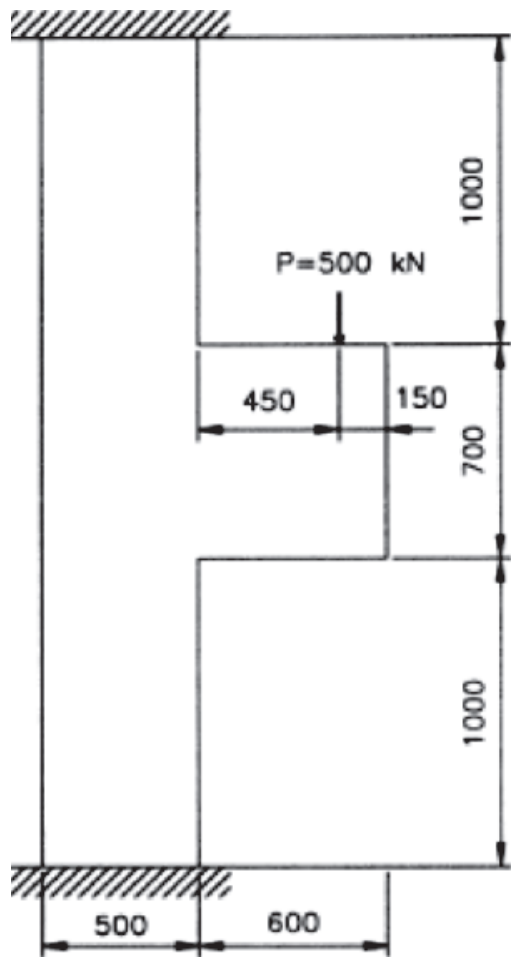

Figure 17

Corbel in a column [15]

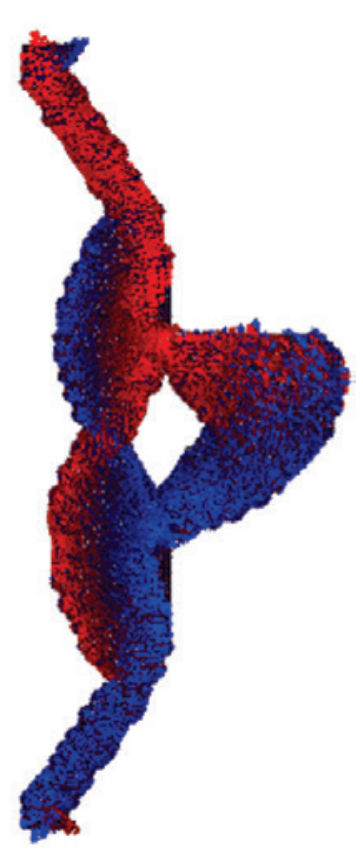

(a)

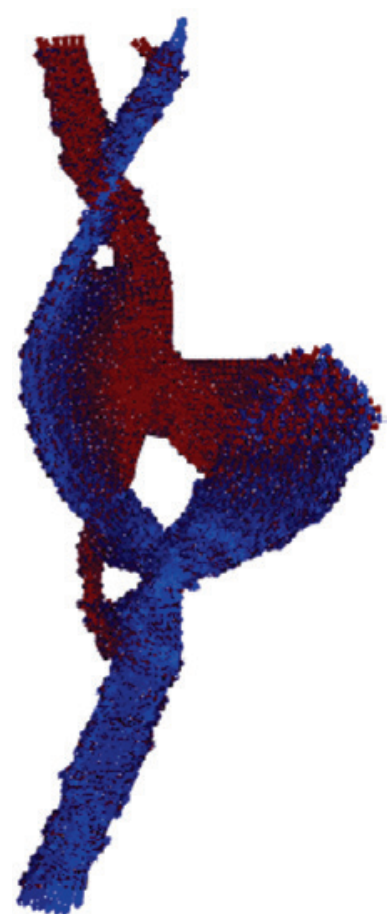

(b)
Figure 18

Solution considering the linear behavior of the material and (b) Solution considering the nonlinear behavior of the material 


\subsection{Example 3: corbel in a column [15]}

The structural element analyzed is a corbel in a column that is loaded by a single force, as detailed in Figure 17. The properties adopted for the material were the same as those reported in Liang et al. [15], with the modulus of elasticity equal to $E=28,567 \mathrm{MPa}$, characteristic compressive strength of concrete equal to $f_{c k}=28.0 \mathrm{MPa}$ and $\gamma_{c}$ equal to 1.40 , and, finally, the and Poisson's coefficient equal to $v=0.15$. The column and corbel width $b=300 \mathrm{~mm}$ were assumed.

To assembly the elements in Abaqus ${ }^{\circledR}$ software, a quadrilateral linear finite element CPS4R (Continuum / Plane-Stress / Shell elements/ 4 Node Element) type was considered. The structure was represented by 3,317 elements and 3,470 nodes. The parameters used for ESO optimization were: Removal Factor (RR) $=4.0 \%$ and Evolution Factor $(E R)=2.0 \%$. The optimum topology was obtained from a volume of approximately $50 \%$ of the initial volume.

The Figure 18 presents responses for compressive stresses distributions (in blue) and traction (in red) for the solutions, considering the linear and non-linear elastic behavior of the material.

The respective strut-and-tie obtained models are presented in detail on Figure 19, when the element removal criterion via ESO admits a smaller volume fraction of remaining material.

For the studied example, it can be noticed that the differences found between linear and nonlinear material topologies were significant. The main observed divergence occurs due to the angle between the axial axis elements. In these circumstances, the selection of optimized

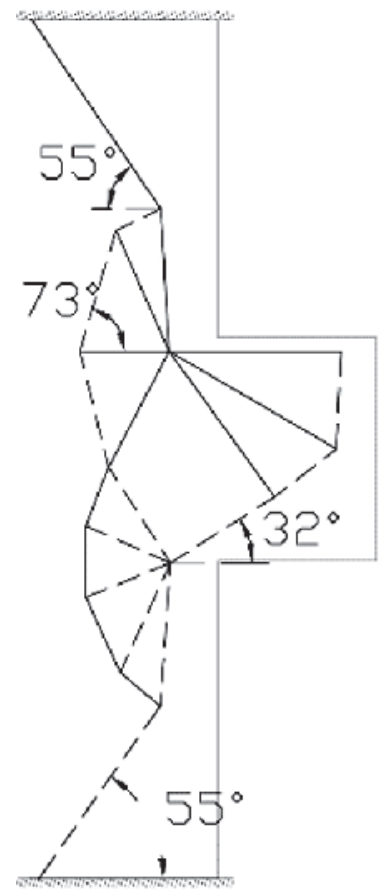

(a)

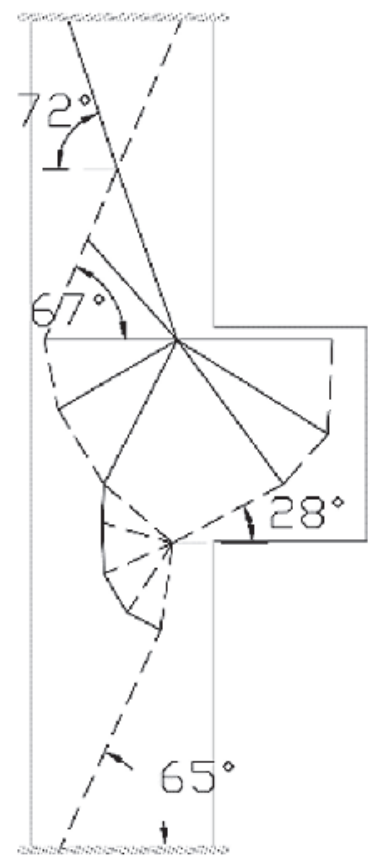

(b)
Figure 19

Strut-and-tie model (a) considering the linear behavior and (b) considering the nonlinear behavior. Dotted lines representing struts and continuous lines representing ties model, with minimum strain energy, or maximum rigidity, is the model represented by the largest number of bars for a truss system and, therefore, the topology indicated in Figure 19(a). From this point, the definition of optimized topology is interpreted for the truss structure, shown in Figure 20(a). The nodes coordinates and the axial forces obtained in the structural analysis of idealized truss of Example 3 are presented in Table 6, Table 7 and Table 8. In this context, the suggested strut-and-tie model corresponds to an envelope of solutions for the possible concrete behaviors, either in linear or non-linear regime. The Figure 21 presents a project sketch of reinforcement concrete in

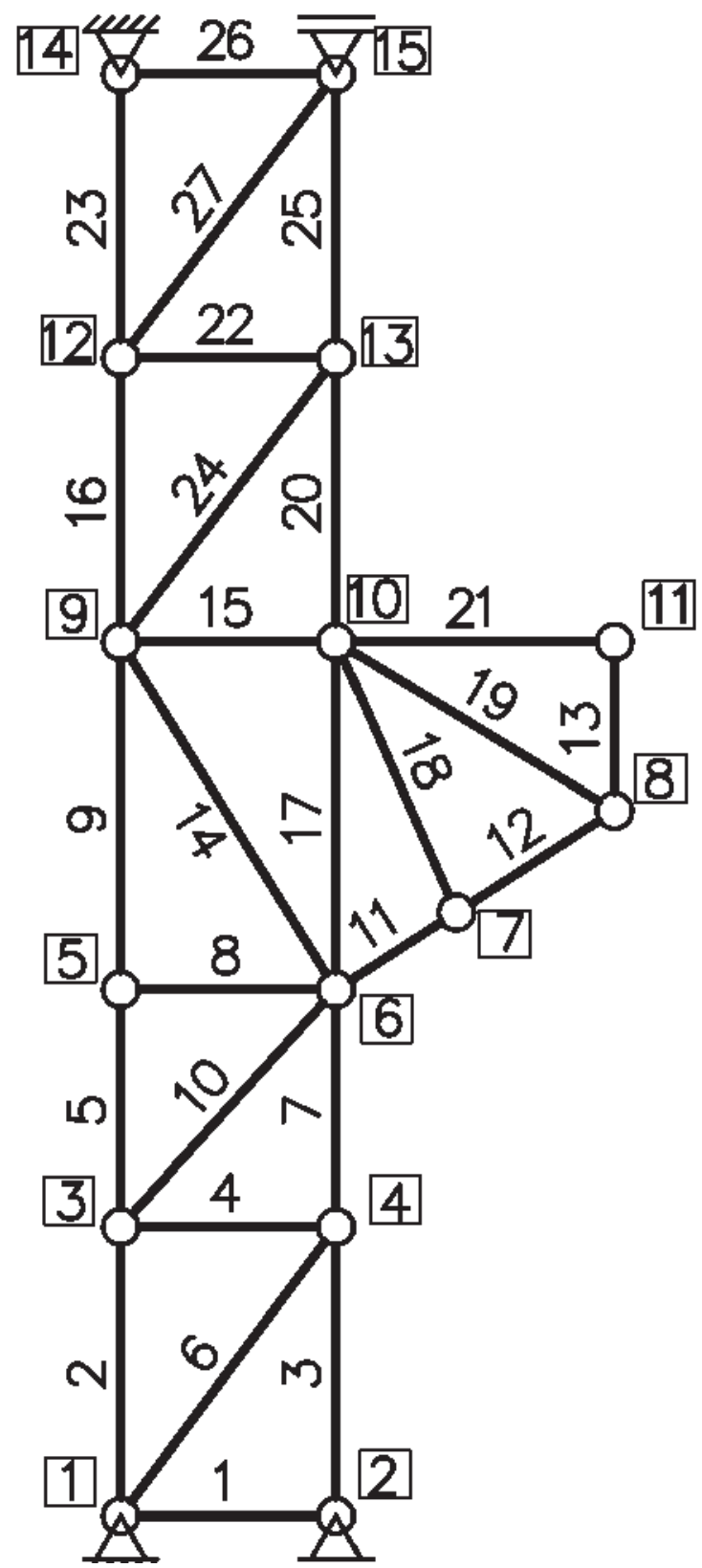

Figure 20

Strut-and-tie model with nodes and member numbers for Example 3 
Table 5

Design axial forces in the bars of the Example 2

\begin{tabular}{cccccc}
\hline $\begin{array}{c}\text { Member } \\
\text { number }\end{array}$ & Type & $\begin{array}{c}\mathbf{F}_{\text {sd }} \\
(\mathbf{k N})\end{array}$ & $\begin{array}{c}\text { Member } \\
\text { number }\end{array}$ & Type & $\begin{array}{c}\mathbf{F}_{\text {sd }} \\
(\mathbf{k N})\end{array}$ \\
\hline 1 & Strut & $-5,500$ & 9 & Strut & $-3,481$ \\
2 & Strut & $-2,753$ & 14 & Strut & $-3,441$ \\
3 & Strut & $-3,481$ & 8 & Tie & 937 \\
4 & Strut & $-3,380$ & 10 & Tie & 937 \\
5 & Strut & $-5,500$ & 11 & Tie & 2,068 \\
6 & Strut & $-3,380$ & 12 & Tie & 2,758 \\
7 & Strut & $-3,441$ & 13 & Tie & 2,068 \\
\hline
\end{tabular}

Table 6

Identification of nodes of the Example 3

\begin{tabular}{cccc}
\hline Node number & $\mathbf{X}(\mathbf{m})$ & $\mathbf{Y}(\mathbf{m})$ & Type \\
\hline 1 & 0,000 & 0,000 & CCC \\
2 & 0,410 & 0,000 & CCC \\
3 & 0,000 & 0,550 & CTT \\
4 & 0,410 & 0,550 & CCT \\
5 & 0,000 & 1,000 & CTT \\
6 & 0,410 & 1,000 & CCT \\
7 & 0,640 & 1,150 & CCC \\
8 & 0,940 & 1,340 & CCT \\
9 & 0,000 & 1,660 & CTT \\
10 & 0,410 & 1,660 & TTा \\
11 & 0,940 & 1,660 & CCC \\
12 & 0,000 & 2,200 & CCT \\
13 & 0,410 & 2,200 & TTा \\
14 & 0,000 & 2,740 & CTT \\
15 & 0,410 & 2,740 & CTT \\
\hline
\end{tabular}

the proposed model. The design of the reinforcement was based on the Brazilian standard [6] and the considered steel was the CA50.

\section{Conclusion}

In this work, three numerical examples were presented to

\section{Table 7}

Design axial forces in the struts of the Example 3

\begin{tabular}{ccc}
\hline Member number & Type & $\begin{array}{c}\mathbf{F}_{\text {sd }} \\
(\mathbf{k N})\end{array}$ \\
\hline 2 & Strut & $-126,800$ \\
3 & Strut & $-161,300$ \\
6 & Strut & $-278,800$ \\
7 & Strut & $-384,800$ \\
10 & Strut & $-247,400$ \\
11 & Strut & $-477,000$ \\
12 & Strut & $-477,000$ \\
13 & Strut & $-500,000$ \\
14 & Strut & $-445,200$ \\
16 & Strut & $-102,700$ \\
24 & Strut & $-275,500$ \\
27 & Strut & $-275,500$ \\
\hline
\end{tabular}

illustrate the design methodology of strut-and-tie models in concrete structures. In order to evaluate the material's behavior in physical linearity and non-linearity, each structure was optimized, assuming linear behavior and later evaluated with non-linear behavior. Then, the strut-and-tie model was proposed from two topologies under the maximum stiffness criteria

With the studies carried out, it was possible to conclude that optimized model conceptions can be idealized from the linear and nonlinear topological concrete optimization. However, it is recommended that, for design purposes, the optimum topology may be adopted so material intense fissures can be avoided.

Considering the numerical simulations carried out, it can be noticed that obtained solutions for the design of strut-and-tie model are relevant for structural engineering, since they provide a contribution to the proposition of analogous systems for the studied cases and still indicates a simplified methodology in the process of strut-and-tie idealization.

\section{Acknowledgements}

The authors acknowledge the financial support granted by CNPq

Table 8

Design axial traction forces

in the ties of the Example 3

\begin{tabular}{ccc}
\hline Member number & Type & $\begin{array}{c}\mathbf{F}_{\text {sd }} \\
(\mathbf{k N})\end{array}$ \\
\hline 1 & Tie & 0,000 \\
4 & Tie & 166,600 \\
5 & Tie & 56,000 \\
8 & Tie & 0,000 \\
9 & Tie & 56,000 \\
15 & Tie & 401,500 \\
17 & Tie & 68,100 \\
18 & Tie & 0,000 \\
19 & Tie & 469,000 \\
20 & Tie & 310,500 \\
21 & Tie & 0,000 \\
22 & Tie & 166,600 \\
23 & Tie & 116,700 \\
25 & Tie & 91,100 \\
26 & Tie & 166,600 \\
\hline
\end{tabular}




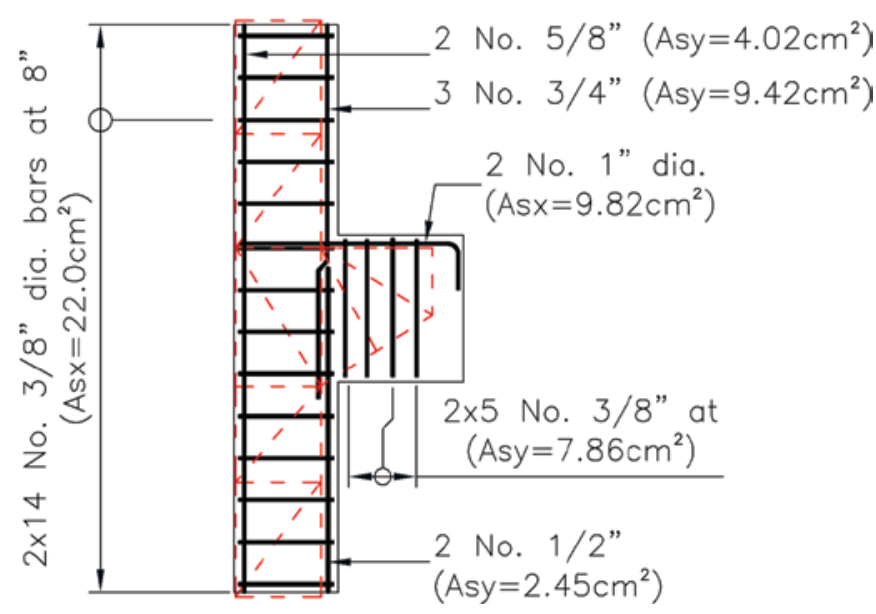

Figure 21

Reinforcement sketch for Example 3

(National Council for Scientific and Technological Development) CAPES (Coordination for the Improvement of Higher Education Personnel), FAPEMIG (Foundation for Research Support of Minas Gerais State) and Federal University of Minas Gerais (UFMG). The authors also thank the revisers for providing such an important work crucial for the paper improvement.

\section{References}

[1] ABAQUS. Abaqus analysis user's manual, Version 6.10, Dassault Systèmes, 2010.

[2] ALMEIDA, V. S.; SIMONETTI, H. L. AND NETO, L. O. Comparative analysis of strut-and-tie models using Smooth Evolutionary Structural Optimization. Engineering Structures, 56, 1665-1675, 2013.

[3] ALMEIDA, V. S.; SIMONETTI, H. L.; NETO, L. O. Análise de modelos de bielas e tirantes para estruturas de concreto armado via uma técnica numérica. Revista Ibracon de Estruturas e Materiais, Volume 6, 139-157, 2013.

[4] AMERICAN CONCRETE INSTITUTE. ACI 318/95 - Building Code Requeriments for Structural Concrete. Detroit, Michigan, 1995.

[5] AMERICAN CONCRETE INSTITUTE. ACI 318/05 - Building Code Requirements for Structural Concrete and Commentary, APPENDIX A: Strut-And-Tie Models". Detroit, 2005.

[6] ASSOCIAÇÃO BRASILEIRA DE NORMAS TÉCNICAS. NBR 6118. Projeto de Estruturas de Concreto - Procedimentos. Rio de Janeiro, 2014.

[7] CANADIAN STANDARDS ASSOCIATION. CSA Standard-A23.3-04 - Design of Concrete Structures. Ontario: Rexdale, 2004.

[8] CHU, D. N.; XIE, Y. M.; HIRA, A.; STEVEN, G. P. Evolutionaty structural optimization for problems with stiffness constraints. Finite Elements in Analysis and Design, v. 21, p. 239-251, 1996.

[9] EUROCODE 2: Design of Concrete Structures. General Rules and Rules for Buildings, 2002.

[10] FÉDÉRATION INTERNATIONALE DU BÉTON. Fib Model
Code 2010 - Final draft. V. 2, Fib nº. 56, p. 53, 2010.

[11] KMIECIK , P.; KAMIŃSKI, M. Modelling of reinforced concrete structures and composite structures with concrete strength degradation taken into consideration. Archives of Civil and Mechanical Engineering. Vol. XI, n³, p.623-636, 2011.

[12] KUMAR, P.;"Optimal force transmission in reinforced concrete deep beams." Computer and Structure, 8(2), 223-229, 1978.

[13] LEE, J.; FENVES, G. L. Plastic-damage model for cyclic loading of concrete structures, Journal of Engineering Mechanics, Vol. 124, No. 8, p. 892-900, 1998.

[14] LIANG, Q. Q.; STEVEN, G.P. A performance-based optimization method for topology design of continuum structures with mean compliance constraints, Computer Methods in Applied Mechanics and Engineering, 191, 13-14, 1471-1489, 2002.

[15] LIANG, Q. Q.; XIE Y. M.; STEVEN, G.P. Topology optimization of strut-and-tie models in reinforced concrete structures using an evolutionary procedure. ACI Struct. J. 97(2): 322-330, 2000.

[16] LIANG, Q. Q.; XIE Y. M.; STEVEN, G.P.; SCHMIDT L.C. Topology Optimization of Strut-and-Tie Models in Non-Flexural Reinforced Concrete Members. International Conference on Mechanics of Structures, Materials and Systems. p.309-315, February, Wollongong, Australia, 1999.

[17] LUBLINER J.; OLIVER J.; OLLER, S.; OÑATE, E. A plasticdamage model for concrete, International Journal of Solids and Structures, v. 25, p. 299-329, 1989.

[18] MACGREGOR, J.G. Reinforced concrete mechanicas and desing. New Jersey. Prentice Hall, 1997.

[19] FRANÇA, M. B. B.; GRECO, M.; LANES, R. M.; ALMEIDA, V. S.; Topological optimization procedure considering nonlinear material behavior for reinforced concrete designs. Computers and Concrete. Volume 17, Issue 1, pp.141-156, 2016.

[20] QUERIN, O. M. Evolutionary structural optimization stress based formulation and implementation. Ph.D. Thesis. Sydney, Australia: University of Sydney, 1997.

[21] SCHLAICH, J; SCHAFER, K; JENNEWEIN, M. Toward a consistent design of structural concrete. PCl-Journal, vol. 32, nr.3, p. 74-150, May/June, 1987.

[22] SCHÄFER, K.; SCHLAICH, J. Consistent Design of Structural Concrete using Strut and Tie Models. Colóquio sobre comportamento e projeto de Estruturas, Rio de Janeiro, 1988

[23] SCHÄFER, K.; SCHLAICH, J. Design and Detailing of Structural Concrete Using Strut-and-Tie Models. The Structural Engineer, v.69, n.06, p.113-125, 1991

[24] SILVA, R. C.; GIONGO, J.S. Modelo de Bielas e Tirantes Aplicados a Estruturas de Concreto Armado. São Carlos: EESC-USP, 2000.

[25] XIE, Y. M.; STEVEN, G. P. A simple evolutionary procedure for structural optimization. Computers \& Structures, v. 49, Issue 5, p. 885-896, 1993.

[26] XIE, Y. M.; STEVEN, G. P. Evolutionary structural optimization for dynamic problems. Computers \& Structures, v.58, Issue 6, p.1067-1073, 1996.

[27] XIE, Y. M.; STEVEN, G. P. Evolutionary Structural Optimization. Springer-Verlag, Berlim, 1997. 